\title{
Do costs matter in ASP sourcing decisions?'
}

\author{
Vincenzo Morabito. Bocconi University. Italy. \\ vincenzo.morabito@unibocconi.it
}

Stefano Pace. Bocconi University. Italy. stefano.pace@unibocconi.it

\begin{abstract}
This paper on Application Service Providers investigates why organizations select an ASP as a form of IS sourcing. To achieve this, we set the ASP within the context of literature on Neoclassical and Resource-Based View (RBW) theories. The results revealed that costs matter little in ASP sourcing decisions. The ASP is chosen not simply as a cost reducing alternative, but moreover, when companies detect an IS gap. Our study presents some managerial implications that affect both customers and ASPs.
\end{abstract}

Key words: ASP, core competence, fluid capability, IS asset, IS capability, IS gap, IS resource, rental propensity, Resource Based Theory, sourcing decision.

\section{INTRODUCTION}

Information systems sourcing continues to be a relevant and problematic issue for companies in today's global environment. As for its relevance, since Eastman Kodak's landmark outsourcing of IT services (Applegate and Montealegre, 1991), the outsourcing industry has been growing at a staggering rate of approximately 20 percent a year (Caldwell, Violino et al., 1997) while in 2001worldwide spending

\footnotetext{
${ }^{1}$ We acknowledge the insightful comments made on an earlier draft of this work by anonymous reviewers. We would also like to thank Doctor Sandro Fazzolari, Ph.D., for his help in editing the text.
} 
on IT outsourcing services reached almost $\$ 64$ billion. Regarding the problematic aspect, the growing number of vendors and services available in the marketplace certainly offers more selection and service types, but this complicates the decision making process as well as contracting and management issues.

In order to contribute to the IS literature with specific focus on sourcing, this paper aims at analyzing the sourcing drivers of the Application Service Provider (ASP) phenomenon. An ASP is a Net-based IS architecture whereby customers use software applications made available over the Internet by an ASP company on pay-as-you-go pricing schemes that are somewhere between paying a fixed price and renting.

This study investigates if costs matter in ASP sourcing decisions by considering prior published studies on outsourcing and a limited number of scholarly studies that have never been published before.

Our thesis is that an ASP is selected as a new and viable strategic option as apposed to the outsourcing alternative. The difference between the two alternatives may appear to be subtle since both delegate the responsibility of the service in question to third parties. However, outsourcing refers to the buying of service outright whereas ASPs rent their service and moreover on a need or per user basis. Nevertheless, it is our contention that costs matter little in the ASP sourcing decision because an ASP is primarily selected to fill an organization's IS resources gaps rather than attaining cost advantages from supposed economies of scale and scope typical of outsourcing vendors. In reality, an ASP is fundamentally different from outsourcing solutions because of its strategic value. It is a fluid IT capability that does not require companies to acquire tangible assets, since IS capabilities can be directly introduced into existing infrastructure. Our results confirmed our thesis, showing that an ASP is selected when a company detects an IS resource gap, and not as a new alternative to reduce IS costs.

The managerial implications affect both customers and ASPs. As for the customers, an ASP can be considered an easy way to add IS capabilities to the firm in a fast and reliable way when compared to buy or make alternatives. Similarly our results suggest that ASPs are in a position to analyze the IS gaps of prospective clients, thus obtaining efficient market segmentation upon which they can target 
future clients. Our research also suggests that ASPs focus on providing centralized capabilities to customers, rather than mere software, thus increasing their value proposition.

The paper is therefore structured as follows. Section 2 describes the different types of IS sourcing available to firms, positioning rental as a third innovative way to satisfy the IS needs of a company. Section 3 examines the ASP in detail highlighting those elements that render it competitive. Sections 4 and 5 introduce hypotheses, constructs and operational elements thereof. Section 6 illustrates the empirical research which explores the drivers that lead a company to select an ASP as an IS solution. Finally, results, discussions and research limitations are presented.

\section{INFORMATION SYSTEMS SOURCING AND OUTSOURCING}

Studies on information systems sourcing decisions have been of great interest to companies (Lacity and Willcocks, 1998; Dibbern, Goles et al., 2004). Until recently, theoretical studies about information systems sourcing have focused on IS outsourcing. While sourcing refers to different procurement contractual model practices (Lacity and Willcocks, 1998), the term outsourcing refers to a specific contractual practice where an external vendor providing a single basic function to the customer assumes operational control over the customer's technology assets (Dibbern, Goles et al., 2004). In IS outsourcing the external vendor typically assumes the data centre control. The IS outsourcing literature has viewed the outsourcing process as two distinct but related streams: outsourcing success (McFarlan and Nolan 1995; Kern and Willcocks, 2002a) and the determinants of IS outsourcing (Loh and Venkatraman, 1992). Our aim is to contribute to the studies that focus on outsourcing determinants and in doing so hope to represent one of the first studies that analyze the ASP phenomenon by pointing out which decisional factors affect its adoption.

The evolving literature on outsourcing determinants explains why IS outsourcing occurs. The reasons cited for IS outsourcing can be classified into three main categories: (1) economic and financial, (2) business and (3) technological and strategic. 
Economic and financial reasons for IS outsourcing include cost reduction and cash generation. Cost reduction and control are often given as main reasons for IS outsourcing (Loh and Venkatraman, 1992; Arnett and Jones, 1994; Lacity, Hirschheim et al., 1994; Loh, 1994; Alpar and Saharia ,1995; McFarlan and Nolan, 1995; Palvia 1995; Slaughter and Ang, 1996; Segupta and Zvirian, 1997; Ang and Straub, 1998; King, 2001). It is commonly believed that an outside vendor can provide the same level of service at a lower cost than an internal IS department. The often cited rationale is that the vendor typically has better economies of scale, better access to lower cost labour pools and more focused expertise in managing IS. Generating cash (Lacity, Hirschheim et al., 1994; McFarlan and Nolan, 1995) is often a consequence of transferring IS personnel and assets to an outsourcer by lowering the debt/capital ratio and by balancing receipts and expenditures.

From a business point of view, organizations may outsource their information systems to simplify management's agenda and provide for more focus on the firm's core business (Lacity, Hirschheim et al., 1994; Cross, 1995; McFarlan and Nolan, 1995; Palvia, 1995; Slaughter and Ang, 1996). Effective IS management requires senior management commitment and expertise. If executives do not see a strategic role for IS, then IS outsourcing is often viewed as a means of conserving managerial effort thus allowing them to focus on areas with greater strategic potential. Using and not generating information seems to be more important to top executives. In other words, rather than spend time and resources building an internal computing infrastructure, many senior executives believe that effort should be concentrated on the effective use of information, new analytical data and whatever other targeted information IS can generate to improve management's responsiveness to market changes (Teng, Cheon et al., 1995).

Our third point expresses a broad (and comprehensive) consensus in the literature about the existence of "technological" reasons for IS outsourcing (Loh and Venkatraman, 1992; Arnett and Jones, 1994; Grover, Cheon et al., 1994; Lacity, Hirschheim et al., 1994; McFarlan and Nolan, 1995; Palvia, 1995; Teng, Cheon et al., 1995; Slaughter and Ang, 1996). Due to rapid technological advances, a firm's IS department may lack or at least lag behind in "IS capabilities" such as the most current expertise and the latest equipment. IS outsourcing, in this case, can be used to create or upgrade an IS infrastructure without substantial capital investments. Firms also tend to outsource to improve the quality of their IS. For 
example, firms may be dissatisfied with the quality and timeliness of development and maintenance or with the quality of the information provided. The succinct corporate saying that driving an IS and not being driven by one is widely held to be synonymous with a system's effectiveness. In some cases, for example, following a major system failure or a breakdown in IS performance, substantial financial losses for the company may result. Outsourcing is a viable alternative to managing this great risk. Firms also outsource to gain access to technical talent and to upgrade their information systems. The firm might be unable to attract the talent needed to develop or maintain systems on a given hardware and software platform. Via outsourcing, such talent is provided for by the outsourcer and, more importantly, the system (hardware and software) is upgraded and properly maintained by the outsourcer.

From a strategic point of view, considering an information system as an information resource that contributes to its competitive advantage, a company cannot do without an active management and control of information system resources and resulting flows. In line with the above, companies often have the propensity to secure access to critical IS resource from the external environment (King and Grover, 1991).

Finally, where some firms may choose to outsource their IS to reduce and control costs, others see this as a risk. Indeed some companies whose very core business is IS based are not likely to outsource the very capabilities they provide other companies. While freeing up decision making focus for executives is a plus to certain businesses, other companies cannot provide themselves with this luxury. But for those who can, the decision to outsource or choose an ASP remains an important one. In order to attempt to contribute to the literature on ASP selection, let us now look at why ASPs are chosen and how important cost reductions are in that decision making process.

\section{DEFINITION AND ARCHITETTURE OF AN ASP}

The Application Service Provider Consortium defines an ASP as an organization which "manages and delivers application capabilities to multiple entities from a data center across a wide area network (WAN)" (Cherry Tree \& Co, 1999). An organization can get access to different software applications delivered by the ASP 
over the Internet on an as-needed basis, similar to electricity, gas and water (Currie, Desai et al., 2004). The user "rents" IS resources (Bharadwaj, 2000; Wade and Hulland, 2004) for a subscription fee or for fairly complex pay-as-you-go pricing schemes that are somewhere in the middle of paying a fixed price and renting. We can consider the ASP model from a technological and operational point of view. Firstly, from a technological point of view, an ASP concentrates all the software complexity in its own data center. The ASP offers customers the opportunity to benefit from very complex application services (i.e. ERP) without incurring in high up-front investments in software licences, hardware and specialized human resources. An ASP is a one-to many model, where an application will be offered to numerous customers across different sites (Currie and Seltsikas, 2001). This opportunity is particularly relevant for Small and Medium Enterprises that often cannot afford the costly investments required by technology. Secondly, from an operational point of view, the customer interacts only with the ASP, whose role is to manage all of the relationships with each player involved in the service "production" (i.e. software companies, software analysts). The ASP is the customer's sole provider of IS, a fact that also simplifies IS management for that customer. The web of links between the ASP and other firms, whose collaboration is necessary to maintain a high service level, is invisible to the customer as it is the ASP that has to coordinate this web of relationships. Usually, these relationships are regulated by medium-to-long-term contracts between the ASP and its clients. Moreover, through an ASP, customers always have an updated IS, which can be upgraded with little or no effort.

The concept of ASP, or "software as a service", was first introduced in 1998, therefore, the ASP market is relatively new. Following a hype, the ASP market slowed down, but today it is spreading world-wide since firms have begun to appreciate the benefits of ASPs. In particular, recent research by the Gartner Group highlighted that, by $2004,70 \%$ of companies will selectively outsource applications using a variety of traditional outsourcers, niche application vendors, offshore providers and ASPs (0.8\%). World-wide spending on IT outsourcing services reached almost $\$ 64$ billion in 2001. In 2000, IT outsourcing represented about $30 \%$ of IT budgets. This tendency to outsource IS resources may signal the issues that a firm often has to deal with when managing increasingly complex IS projects and resources. Such tendency represents a tremendous opportunity for those solutions furnished via ASPs. 


\section{RESEARCH HYPOTHESES}

\section{Hypotheses}

Based upon the concept of ASP as a net-based software rental company we would expect that, as the literature on IS outsourcing suggests, ASP sourcing decisions are propelled by a perceived production cost advantage. In this paper, we introduce another driver besides the purely cost based one, namely, ASP sourcing decisions as a corporate strategy to fill IS capabilities gaps. In the next two sections, we develop these two hypotheses.

\section{Cost advantage}

From a neoclassical point of view, any business organization can be considered as a "production function" motivated by profit-maximization (Williamson, 1975). On one hand, organizations rely on the marketplace for goods and services for which they have comparative cost disadvantages. On the other hand, they provide the market with goods for which they have a cost advantage. According to this view, firms would select sourcing option opportunities according to comparative cost advantages. Any sourcing option opportunity is treated as an economic makeor-buy decision, that is, a decision that compares internal operation production costs versus marketplace price offers. Consequently, when making a decision on IS, a firm would preferably select the "rental" option, versus the "make" or "buy" alternatives, in as much as its economic advantages become more readily apparent. In other words, a firm would select to buy an ASP application service based upon the comparative costs relating to both internalizing and outsourcing of information systems (cost of purchasing vendor services plus cost of contract monitoring) versus the price it has to pay to ASPs for the same IS services. In this context we define "rental" propensity as the firms intention to rely on an ASP for their IS needs. In a strict sense, the variable rental propensity would not measure the actual use of ASPs by a customer. Similarly, the measurement of ASPs actually adopted would limit the sample exclusively to those companies which have already chosen an ASP, thereby introducing bias in the results. What we would like to measure is not whether a company would, or whether it already has chosen an ASP or not, but rather, the reasoning behind their choice or eventual choice. This decision ought 
not be constricted outright by boundaries such as budgets devoted to IS. Albeit recent surveys on IS management have shown that "IS cost containment" is a major concern in the entire industry (Assinform, 2005). Therefore:

H1: The higher the comparative production cost advantage gained from IS ASP services, the greater the "rental" propensity.

\section{IS resources gaps}

According to the Resource-Based View for firms (Wernerfelt, 1984), both the availability and quality of resources would explain the difference in the performance of companies belonging to the same industrial sector and the presence of sustainable competitive advantage in a specific business organization (Wernerfelt, 1984; Prahalad and Hamel, 1990). Within this framework, resources are supposed to be tangible and intangible. Tangible resources refer to fixed assets and working capital; intangible resources refer to competencies and routines (Nelson and Winter, 1982; Prahalad and Hamel, 1990; Grant, 1996; Teece, Pisano et al., 1997), that are part of the knowledge an organization uses as part of its ongoing activities. Competencies are basically knowledge-based routines (Nelson and Winter, 1982) made idiosyncratic by a lengthy accumulation process. By arranging and coordinating groups of tangible and intangible resources or competencies, company processes tend to work better (Grant, 1991; Amit and Schoemaker, 1993; Grant, 1996).

The Resource-Based View allows us to observe the rental (or ASP) choices from the competencies point of view. In particular, decisions concerning the choice of the ASP option are greatly influenced by the gap (in terms of both quantity and quality) of IS competencies to be filled in order to achieve a perfectly functioning system (Grant, 1991). By comparing the RBV to the IS literature (Loh and Venkatraman, 1992; Arnett and Jones, 1994; Grover, Cheon et al., 1994; McFarlan and Nolan, 1995; Palvia, 1995; Teng, Cheon et al,. 1995; Slaughter and Ang, 1996) and because of fast technological advances, a firm's IS department may lack "IS capabilities" such as up-to-date equipment or software expertise.

Therefore, we can expect a company lacking internal IS competencies to externally acquire what it needs. The rental solution may provide better performance compared to buy or make decisions. By purchasing external software, the customer 
does not internalize the competencies embedded in the purchased product. Conversely, an ASP allows for a better fit with the existing routines of the customer as it is unlikely that a single software supplier might have all the solutions needed by a given company. Therefore different firms each supply various solutions via ASPs and the customer has an excellent fit for each of its core competencies. An ASP plays the role of a hub that collects all the solutions/services of the software market and then rents those solutions/services that better suit the specific requirements of a customer. Within the broad range of solutions in the ASP's "shelves", the customer can easily find what it is looking for. The idiosyncratic nature of firms is satisfied by the ASP. The make decision is also at odds compared to the rent one because a company cannot internally make software in such an easy and cost effective way so as to satisfy all of the different company needs. We can summarize the above in the following hypothesis $\mathrm{H} 2$.

H2: The higher the IS resources gaps, the greater the "rental" propensity.

\section{OPERATIONAL AND RELATIONSHIP CONSTRUCT}

\section{Operational Construct}

The research framework aims at explaining the propensity to rent of a company (dependent variable) in terms of two independent variables: cost advantage and IS resources gap. The first independent variable is drawn from IS outsourcing literature and refers to pre-eminent traditional reasons for IS outsourcing. The second independent variable refers to our consideration of ASP service specificity.

The following are the three variables conceived and measured in this study:

1. ASP-Rental propensity (PROPRENT) is the dependent variable. It refers to the firms intention to rely on an ASP for their IS needs. This variable can be implemented in three components: operational, security and legal. The operational aspect is the degree of efficiency perceived as a consequence of the ASP (or Service Level Agreement, SLA). Security refers to the perceived capability of the ASP to fix any security and reliability issues relative to customer Information Systems. The legal perspective refers to the informant's determination to sign a contract with an ASP. 
2. Cost production advantage (VCOPRO) is the perceived cost advantage of an ASP compared to internal IS management. Production cost is subdivided into three elements: hardware, software and IS human resources.

3. IT Resource Gaps (GINCAP) refer to perceived gaps between internal IS resources and the resources required to implement a strategic IS. Based upon Grant's concept of IT resources (Grant, 1995), gaps in IT resources are articulated on two levels: technological and human resources. As for the technological perspective, we considered the need to rent IT infrastructures or physical IT assets (Ross, Beath et al., 1996; Weill, Broadbent et al., 1996), especially hardware and software (Hall 1997; Srivastava, Shervani et al., 1998; Wade and Hulland, 2004). As to human resources, we considered the gap in a firm's IT skills (Ross, Beath et al., 1996; Bharadwaj, 2000; Wade and Hulland, 2004) that may be filled by ASPs.

\section{Construct relationships articulation}

The two independent (Vcopro and Gincap) variables show a systemic relationship.

IS resource gap - Cost advantage. If managerial attention is focused on filling IS resource gaps, then focus on cost advantages is reduced. In fact, when resource-related considerations are made during the decision process, price issues may still matter but they are not be the most important drivers in the sourcing decision. As a consequence, the firms that internally lack the skills to build and manage their information systems will try to fill the gap in the IS capabilities rather than concentrate on plans for the reduction of operational costs. Although the theory herein presented would suggest two distinct approaches, it is possible to find a balance between the two variables. Figure 1 shows the framework of the hypotheses.

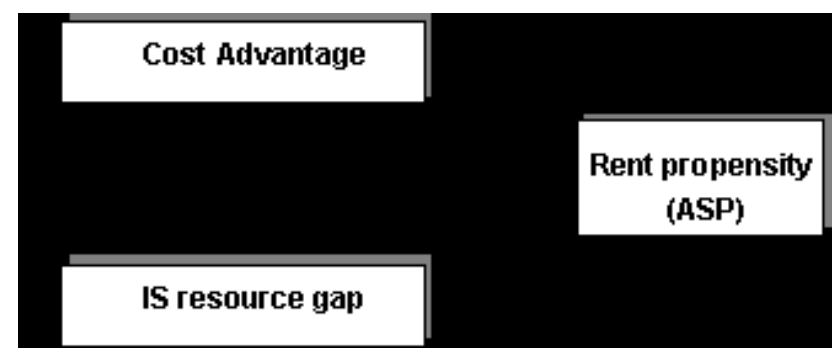

Figure 1. Structure of Hypotheses 


\section{EMPIRICAL STUDY}

\section{Methodology}

In order to validate the hypotheses, we administered a questionnaire. Items in the questionnaire measured concepts in the research model. Items were measured on a 7-point Likert scale. A draft instrument was qualitatively and quantitatively pre-tested to make sure that the final version would be equally valid for use with a large sample. The pilot study ensured clarity of the questionnaire and ascertained that theory-based items tapped issues of concern in IS sourcing decisions. The research design included, as control variables, the size of the company, its industry, the role of respondents within the organization and whether the organization had ever outsourced IS or not.

\section{Sample}

The questionnaire was administered to 102 top executives. The majority of them belonged to Italian companies, although not exclusively. The profiles of participants were indeed diverse since they represented various industry sectors and belonged to all relevant functions within a company (Production, $R \& D$ etc.). The companies virtually represented all revenues levels, from small businesses to large conglomerates and included both those that had already outsourced IS and those that had not yet committed to these types of strategic alternatives.

\section{Research design}

The 102 questionnaires were analyzed in two steps:

1. A construct validation using factor analysis in order to validate the scales for which we could not rely upon the literature.

2. An analysis using linear regression between the two independent variables and the dependent variable (propensity for ASP).

We defined three variables:

1. Proprent: rental propensity (dependent variable); 
2. Vcopro: cost production advantage (independent variable);

3. Gincap: gap in IS resources (independent variable).

For each variable, we used different items that we validated. The construct validation was developed in two stages. In the first stage, we used a factor analysis for each of the three variables in order to discard the items that would not aggregate well in one factor, since these would not be a reliable tool for measurement of the variable. For each variable, we extracted the items with a higher loading factor (higher than 0.7) and with an inter-items reliability Cronbach's Alpha equal to or higher than 0.7. Upon completion of the first stage, three items for each variable were retained. Table 1 gives an overview of the items being considered, their factor loadings and their Cronbach's Alpha for each variable.

\begin{tabular}{|l|c|c|}
\hline MEASUREMENT ITEMS & $\alpha$ & Factor Loadings \\
\hline DEPENDENT VARIABLE & & \\
\hline$\bullet \quad$ Rental Propensity - Proprent & .71 & \\
\hline $\mathrm{y}_{1}-$ I would not hesitate in signing an ASP contract & .815 \\
\hline $\begin{array}{l}\mathrm{y}_{2}-\text { The ASP would help me to solve any efficiency issues related to an internal } \\
\text { IS }\end{array}$ & & \\
\hline $\begin{array}{l}\mathrm{y}_{3}-\text { Acquiring application services from an ASP would fix any security and } \\
\text { reliability problem with our IS }\end{array}$ & & \\
\hline INDIPENDENT VARIABLE & & \\
\hline$\bullet \quad$ Gaps in information system capabilities - Gincap & & \\
\hline $\mathrm{x}_{1}-$ I believe that my company has a gap in hardware resources & .88 \\
\hline $\mathrm{x}_{2}-$ I believe that my company has a gap in software resources & & .881 \\
\hline $\mathrm{x}_{3}-$ I believe that my company has a gap in IS human resources & & .886 \\
\hline$\bullet \quad$ Cost production advantage - Vcopro & & .914 \\
\hline $\mathrm{x}_{4}-$ I believe that ASP will reduce our hardware costs & .78 & \\
\hline $\mathrm{x}_{5}-$ I believe that ASP will reduce our software costs & & .860 \\
\hline $\mathrm{x}_{6}-$ I believe that ASP will reduce our IS human resources costs & .817 \\
\hline
\end{tabular}

Table 1 . Factor analysis and reliability analysis for the three variables

In the second stage of variables validation, we performed a confirmatory factor analysis (Table 2) to assess if the items validated during the first step would still be reliable and would aggregate together in three distinct factors (one for each of the variables), when considered together and not separately as in the first stage. The analysis confirmed the expectations and we are confident that all devised items are a reliable measurement of the variables. 


\begin{tabular}{|l|r|r|r|}
\hline MEASUREMENT ITEM & \multicolumn{3}{|c|}{ COMPONENT } \\
\hline DEPENDENT VARIABLE & $\mathbf{1}$ & $\mathbf{2}$ & \multicolumn{1}{|c|}{$\mathbf{3}$} \\
\hline - Netsourcing Propensity - Proprent & & & \\
\hline $\mathrm{y}_{1}$ &, 795 & & \\
\hline $\mathrm{y}_{2}$ &, 821 & & \\
\hline $\mathrm{Y}_{3}$ &, 485 & & \\
\hline INDEPENDENT VARIABLES & & & \\
\hline$\bullet \quad$ Gaps in information system capabilities - Gincap & & & \\
\hline $\mathrm{x}_{1}$ & &, 679 & \\
\hline $\mathrm{x}_{2}$ & &, 913 & \\
\hline $\mathrm{x}_{3} \quad$ & &, 812 & \\
\hline$\bullet \quad$ Cost production advantage - Vcopro & & &, 839 \\
\hline $\mathrm{x}_{4}$ & & &, 804 \\
\hline $\mathrm{x}_{5}$ & & &, 723 \\
\hline $\mathrm{x}_{6}$ & & & \\
\hline
\end{tabular}

(*) Extraction Method: Principal Component Analysis. Rotation Method: Varimax with Kaiser Normalization. Rotation converged in 5 iterations.

Table 2. Confirmatory factor analysis*

Then, we built the correlation table (Table 3).

\begin{tabular}{|l|c|c|c|}
\hline & PROPRENT & GINCAP & VCOPRO \\
\hline PROPRENT & 1 & $.660(* *)$ & $.418(* *)$ \\
\hline GINCAP & & 1 & $.423(* *)$ \\
\hline VCOPRO & & & 1 \\
\hline
\end{tabular}

(**) Correlation is significant at 0.01 level (2-tailed).

Table 3. Correlation table**

The correlation table shows a significant albeit low correlation between the two independent variables. This result can be explained by two considerations, one arguing that this is due to the fact that some respondents in the sample considered the ASP as a cost reduction strategy and the other that even when an ASP is selected to fill IS resource gaps, cost concerns still hold true and therefore should always be monitored.

Following the reliability analysis, we set a linear regression between the propensity for ASP (dependent variable) and the two validated independent variables: gaps in IS capabilities and cost production advantage. In detail, we estimated the following linear regression model: 
PRPOPRENT $=$ Constant $+\beta_{1}$ VCOPRO $+\beta_{2}$ GINCAP $+\beta_{3}$ Setatt $+\beta_{4}$ Cla $\_$fatt $+\varepsilon$

Setatt and Cla-fatt are control variables, the industry and the total revenues of the company, respectively. Table 4 and 5 show the results.

\begin{tabular}{|c|c|c|c|c|}
\hline MODEL & R & R SQUARE & ADJUSTED R SQUARE & $\begin{array}{c}\text { STD. ERROR OF THE } \\
\text { ESTIMATE }\end{array}$ \\
\hline 1 &, $721(\mathrm{a})$ &, 520 &, 489 &, 92412 \\
\hline
\end{tabular}

a Predictors: (Constant), gincap, vcopro

Table 4. Model summary

\begin{tabular}{|l|r|r|r|r|}
\hline \multirow{2}{*}{$\begin{array}{c}\text { MODEL - DEPENDENT VARIABLE: PRO- } \\
\text { PRENT }\end{array}$} & \multicolumn{2}{|c|}{$\begin{array}{c}\text { UNSTANDARDIZED CO- } \\
\text { EFFICIENTS - BETA }\end{array}$} & & \\
\cline { 2 - 3 } & \multicolumn{1}{|c|}{ BETA } & \multicolumn{1}{c|}{ STD. ERROR } & \multicolumn{1}{c|}{ T } & \multicolumn{1}{c|}{ SIG. } \\
\hline (Costant) &, 127 &, 554 &, 229 &, 819 \\
\hline Gaps in information system capabilities - Gincap &, 671 &, 107 & 6,286 &, 000 \\
\hline Cost production advantage - Vcopro &, 189 &, 104 & 1,815 &, 074 \\
\hline
\end{tabular}

Table 5. Model linear regression

As shown in the tables, both hypotheses are supported with different significance levels. The Vcopro (Cost production advantage) variable is significant with a 90\% level, $\beta_{1}=.189$. The Gincap (Gap in information system capabilities) variable is statistically significant with a $99 \%$ level of confidence, $\beta_{2}=.671$. We can conclude that the propensity to rent through an ASP is mostly due to the desire to fill IS gaps, rather than to pursue a production cost advantage. Costs, according to our data, seem to matter little in ASP sourcing decisions.

\section{DISCUSSION AND CONCLUSIONS}

The results show that the propensity for ASPs and related renting solutions is mainly due to the desire to fill IS gaps. This result confirms the idea that the ASP is a strategic capability that is able to satisfy a company's needs for IT capabilities better than the traditional buy or make solutions. The ASP is not primarily chosen as an alternative to reduce costs, but rather it is selected when a company detects IS gaps and its focus on cost advantages has little or no impact at all on this decision.

The managerial implications affect both customers and ASPs. As for customers, an ASP can be considered as a viable and strategic decision which can provide a strategic competitive advantage (SCA). It is a way to let IS enter the firm in a fast 
and reliable manner and under the form of a capability rather than as an asset. The buy and make options are still viable solutions, even though ASPs seem to represent a third solution to be taken in consideration by industries characterized by a high level of competition and need to fill IS gaps in a simple and expedient way.

As far as ASPs are concerned, customers or potential ones should be considered after an IS gap analysis is made. This information would prove to be useful in targeting the specific needs of future customers and segmenting them into industry groups or clusters. Our research also suggests that ASPs focus on providing central capabilities to customers, rather than a mere provisioning of software, thus increasing their value proposition. Also, ASPs should not focus exclusively on price, since - as shown by the results - cost advantages alone do not affect a customer's decision to rent.

What is worthy of careful consideration on the ASP front is the ability to provide customers with capabilities, that is, being constantly updated with IS innovation in order to develop new solutions for new strategies. And that these new solutions need to be deliverable in the fastest and most direct way to customer IS infrastructure. The inherent features of an ASP render this solution a fluid capability that can be easily imported from outside the firm to be idiosyncratically utilized from within the firm. ASPs do not require companies to acquire tangible assets, since IS capabilities can be directly introduced, thanks to their fluid nature. This is consistent with recent streams of thought in Business-to-Business sectors (Golfetto and Mazursky 2004). This literature stream claims that suppliers do not provide their customers with products, but with capabilities.

This study is certainly not without its limitations. Clearly one of these may be the lack of external validity of results. We did our best to take some precautions to extend the validity of the results to an ample range of industries in as much as our sample used different managerial levels, representing various industries with different revenues levels. We also considered companies that had already outsourced and others that had not. A greater sample in terms of number and geographical provenance would help in this sense.

The correlation actually showed some connection between our alternative independent variables, but we attributed this to the fact that some respondents considered ASPs as cost reduction capabilities and not as mere IS gap fillers. A 
further inquiry into the nature of these firms would extend the conclusions of our research and would also show the level of sophistication of the purchasing behavior of firms when IS is at stake.

\section{REFERENCES}

ALPAR, P.; SAHARIAA. N. (1995): "Outsourcing Information Systems Functions: An Organizational Economics Perspective”, Journal of Organizational Computing 5(3): 197-217.

AMIT, R.; SCHOEMAKER, P. (1993): "Strategic assets and organizational rent", Strategic Management Journal, 14: 33-46.

ANG, S.; STRAUB, D. W. (1998): "Production and Transaction Economies and IS Outsourcing: A Study of the U.S. Banking Industry", MIS Quarterly, 22(4 December,): 535-552.

APPLEGATE, L. M.; MONTEALEGRE, R. (1991): Eastman Kodak: Managing Information Systems Through Strategic Alliances, Boston, MA, Harvard Business School.

ARNETT, K. P.; JONES, M. C. (1994): "Firms that Choose Outsourcing: A Profile", Information \& Management, 26(4): 179-188.

ASSINFORM (2005): The ICT market in Italy. Milan, Assinform-Aitech.

BHARADWAJ, A. S. (2000): "A Resource-based Perspective on Information Technology Capability and Firm Performance: An Empirical Investigation", MIS Quarterly, 24(1): 169-196.

CALDWELL, B.; VIOLINO, B. ET AL. (1997): "Hidden partners, hidden dangers" Informationweek, 38-52.

CHERRYTREE \& CO (1999): Application Service Provider Spotlight Report, C. T. Co. Edina, Minnesota.

CROSS, J. (1995): "IT Outsourcing - British Petroleum's Competitive Approach", Harvard Business Review, 73(3): 94-102. 
CURRIE, W.; B. DESAI, ET Al. (2004): "Customer evaluation of application service provisioning in five vertical sectors", Journal of Information Technology, 19: 39-58.

CURRIE, W. L.; P. SELTSIKAS (2001): "Exploring the Supply-Side of IT Outsourcing: Evaluating the Emerging Role of Application Service Providers", European Journal of Information Systems, 10(3): 123-134.

DIBBERN, J.; T. GOLES, ET AL. (2004): "Information system outsourcing: a survey and analysis of the literature", The Data Base for Advances in Information System, 35(4): 6-102.

GOLFETTO, F.; MAZURSKY, D. (2004): "Competence-Based Marketing", Harvard Business Review, December.

GRANT, R. M. (1991): "The resource-based theory of competitive advantage: implications for strategy formulation", California Management Review, 33(3): 114-135.

GRANT, R. M. (1995): Contemporary Strategy Analysis. Oxford.

GRANT, R. M. (1996): "Prospering in Dynamically competitive environments: Organizational Capability as Knowledge Integration”, Organizational Science, 7(4): 375-386.

GROVER, V.; CHEON, M. ET AL. (1994): "An Evaluation of the Impact of Corporate Strategy and the Role of Information Technology on IS Functional Outsourcing", European Journal of Information Systems, 3 (July): 179-190.

GROVER, V.; M. J. CHEON, ET AL. (1994): "A Descriptive Study on the Outsourcing of Information Systems Functions", Information \& Management, 27(July): 33-44.

HALL, R. (1997): Complex systems, complex learning, and competence building. Strategic Learning and Knowledge Management. Sanchez, R. and Heene,, A.;. Chichester, John Wiley. 
KERN, T.; WILLCOCKS, L. P. (2002a): "Exploring Relationship in Information Technology Outsourcing: The Interaction Approach", European Journal of Information Systems, 11(1): 3-19.

KING, W. R. (2001): "Developing a Sourcing Strategy for IS: A Behavioral Decision Process and Framework", IEEE Transactions on Engineering Management, 48(1): $15-24$.

KING, W. R.; V. GROVER (1991): "The strategic use of information resource. An exploratory study", IEEE Transaction on Engineering Management, 38(4): 293-305.

LACITY, M.; R. HIRSCHHEIM, ET AL. (1994): "Realizing Outsourcing Expectations", Information Systems Management, 11 (Fall): 7-18.

LACITY, M. C.; L. P. WILLCOCKS (1998): "An Empirical Investigation Of Information Technology Sourcing Practices: Lessons From Experience", MIS Quarterly, September: 363-405.

LOH, L. (1994): An Organizational-Economic Blueprint for Information Technology Outsourcing: Concept and Evidence. The 15th International Conference on Information Systems, Vancouver, BC, Canada.

LOH, L.; VENKATRAMAN, N. (1992): "Diffusion of Information Technology Outsourcing: Influence Sources and the Kodak Effect", Information Systems Research, 3/4, December, 334-378.

MCFARLAN, F. W.; NOLAN, R. L. (1995): "How to Manage an IT Outsourcing Alliance", Sloan Management Review, 36 (Winter): 9-23.

NELSON, R.; WINTER, S. (1982): An evolutionary Theory of Economic Change. Cambridge.

PALVIA, P. C. (1995): “A Dialectic View of Information Systems Outsourcing: Pros and Cons”, Information \& Management, 29: 265-275.

PRAHALAD, C. K.; HAMEL, G. (1990): "The Core Competence of the Corporation”, Harvard Business Review, 68(3): 79-90. 
ROSS, J. W.; BEATH, C. M. ET AL. (1996): “Develop Long-term Competitiveness through IT Assets", Sloan Management Review, 38 (Fall): 31-42.

SEGUPTA, K.; ZVIRIAN, Z. (1997): "Measuring User Satisfaction in an Outsourcing Environment", IEEE Transaction on Engineering Management, 44(4): 414-420.

SLAUGHTER, S.; ANG, S. (1996): "Employment Outsourcing in Information Systems", Communications of the ACM, 39 (July): 47-54.

SRIVASTAVA, R.; SHERVANI, T. ET AL. (1998): "Market-Based Assets and Shareholder Value: A Framework for Analysis", Journal of Marketing, 62(1): 2-18.

TEECE, D.; PISANO, G. ET AL. (1997): “Dynamic capabilities and strategic management", Strategic Management Journal, 18(7): 509-533.

TENG, J. T. C.; CHEON, M. J. ET AL. (1995): "Decisions to Outsourcing Information System Function: Testing a Strategy-Theoretic Discrepancy Model", Decision Science, 26(1): 75-103.

WADE, M.; HULLAND, J. (2004): "Review: The Resource-Based View and Information System Research: Review, Extension, and Suggestions for Future Research", MIS Quarterly, 28(1): 107-142.

WEILL, P.; BROADBENT, M. ET AL. (1996): Exploring How Firms View IT Infrastructure, The University of Melbourne.

WERNERFELT, B. (1984): “A resource-based view of the firm", Strategic Management Review, 5(2): 513-525.

WILLIAMSON, O. E. (1975): Markets and Hierarchies: Analysis and Antitrust Implications. New York, Free Press. 